\title{
Screening of Anti-Hepatitis B Virus Polypeptides*
}

\author{
Hui Wang ${ }^{1}$, Wenqiong Wang $^{1}$, Jiejie Yang ${ }^{1}$, \\ lin $\mathrm{Hou}^{1}$, Ning $\mathrm{Li}^{1}$
}

\begin{abstract}
${ }^{1}$ Department of Biochemistry and Molecular biology, Medical College, Qingdao University, 38 DengZhou Road, Qingdao, China, 266021

*This work was supported by the Shandong Provincial Natural Science Foundation (No.BS2014YY015) and the Qingdao Postdoctoral Application Research Project (No. 2015159).
\end{abstract}

\begin{abstract}
Objective: HepG2.215 cells are used as an experimental model, the central interaction region (CID) of MxA protein is divided into different regions according to its structure, and different plasmids are constructed to find the most powerful functional polypeptide against hepatitis B virus. Methods: Using full-length MxA plasmid as a template and pCMV-tag-3A as a vector, we constructed plasmids A1, A1A2, and A2A3 according to the CID. The plasmids were sequenced and transfected into HepG2.2.15 cells respectively. 24 hours later, the expression of the plasmid was detected by qRT-PCR. And the expression of HBsAg and $\mathrm{HBeAg}$ were detected by enzyme-linked immunosorbent assay (ELISA). The relative DNA expression of HBV DNA was detected by qRT-PCR. Combined with the peptide structure and the screening results, the segment was again divided into different short peptides, which were constructed into different plasmids and transfected into cells. And we detected the corresponding indicators again. Thereby repeat in this cycle until the shortest functional polypeptide is found. Result: The constructed plasmids were correct and their expression was normal. The expression of HBV DNA, HBsAg and $\mathrm{HBeAg}$ in the $\mathrm{A} 1$ group were significantly lower than that in the other two groups, and it was equivalent to the CID group. Separating the $\mathrm{A} 1$ component into $\mathrm{A} 1^{\mathrm{N}}, \mathrm{A} 1^{\mathrm{C}}$, the results of the test showed that the expression levels of $\mathrm{HBV}$ DNA, HBsAg and HBeAg in the two groups were higher than those in the A1 group and the CID group, and there was no difference between the two groups and the blank group.
\end{abstract}

Keywords: HBV, DNA, Peptide, Plasmid Construction

\section{Introduction}

Chronic hepatitis B virus (HBV) infection is closely related to liver diseases (such as chronic liver dysfunction, cirrhosis and liver cancer)[1]. According to statistics, about 400 million people worldwide are infected with hepatitis B virus, more than one third of them occurs in China, where approximately 1 million people die each year from end-stage of liver disease associated with $\mathrm{HBV}$ infection[2]. At present, antiviral therapy for chronic hepatitis B (CHB) includes IFN- $\alpha$ treatment and nucleoside (acid) analogue treatment[3]. As one of the preferred anti-HBV drugs, IFN-aachieves its antiviral effects mainly by inducing cells to produce antiviral proteins and immunomodulation. Nucleoside drugs act on HBV polymerase to inhibit viral replication, and long-term use can easily cause viral resistance mutations[4]. Moreover, interferon therapy and adefovir treatment can impair renal function. Therefore, the drug resistance of nucleoside drugs and the non-response of IFN- $\alpha$ have been the limitations of current antiviral therapy.
MxA (myxovirus resistance protein A), discovered in 1988, belongs to the superficial family of the kinesin macromolecular GTPase, mainly distributes in the cytoplasm. It is named as anti-mucus virus protein A because it can resist mucus virus. The MxA gene is normally silent, however, when the cells are infected by virus or are highly expressed induced by type I interferon, they produce two direct antiviral factors 2'-5' oligoadenylate synthase 1 (OAS-1) and myxovirus resistance protein A (MxA). Since it is discovered, MxA protein has attracted much attention due to its broad-spectrum anti-RNA virus activity. Recent studies have shown that MxA can also inhibit the replication of DNA virus---Hepatitis B virus[5, 6], but its mechanism of action is not yet clear. Previous studies have indicated that $\mathrm{MxA}$ exerts antiviral function mainly through interaction with hepatitis B virus nucleocapsid, and its key area for exerting antiviral activity is its central interaction region CID[7]. MxA protein plays function in cytoplasm and is $76 \mathrm{KD}$. Whereas, the cell membrane only allows small molecules with a

This article is published under the terms of the Creative Commons Attribution License 4.0 Author(s) retain the copyright of this article. Publication rights with Alkhaer Publications.

Published at: http://www.ijsciences.com/pub/issue/2018-12/

DOI: 10.18483/ijSci.1881; Online ISSN: 2305-3925; Print ISSN: 2410-4477 
molecular weight of less than 500D to pass. So we hope to identify effective peptides with antiviral activity on MxA protein through stepwise screening. The molecular weight reduction will greatly improve its bioavailability, and reduce the difficulty of developing into drug precursors.

\section{MATERIALS AND METHODS}

\subsection{Cell lines and cell culture}

HepG2.215 cells are from Zhejiang University, cultured by DMEM High sugar medium (Hyclone, USA) with $10 \%$ fetal bovine serum (BI). G418 (Beijing solarbio Technology Co., Ltd. G8160) was put into the medium above at the final concentration of $400 \mathrm{ug} / \mathrm{ml}$. All the cells were cultivated in $37^{\circ} \mathrm{C}$ culture box with $5 \% \mathrm{CO} 2$

\subsection{Plasmid construction}

We set MYC-MXA (storage in this laboratory) as a template, pCMV-tag-3A as plasmid carrier, and designed primers based on the target sequence with primer primer 5 Software ( table 1) . With KOD-plus-neo (Japan, Toyobo) high-fidelity enzyme for PCR reaction, according to the instructions, we carried out the reaction procedure with $1 \%$ agarose gel electrophoresis, 110v,30min. Cutting glue for DNA recovery (Axygen glue Recovery Kit), the specific steps were detailed in the instructions. Connect the destination fragment to the carrier. Colony inoculation was picked to add antibiotics to the rocker tube culture for 14-16 hours. After the sequencing results were correct, we extracted plasmid according to the plasmid Extraction Kit (TRANE) manual and saved under the condition of $-20^{\circ} \mathrm{C}$.

\subsection{Total RNA extraction and real-time PCR}

The total RNA was extracted by Takara Rnaiso plus after cell treatment, and the reverse transcription was carried out using transcript one-step gDNA Removal and cDNA Synthesis supermix Reverse Transcription kit, with a reaction condition of $42^{\circ} \mathrm{C} 15 \mathrm{~min}, 85^{\circ} \mathrm{C} 5 \mathrm{~s}$, the synthesized cDNA is preserved in $-80^{\circ} \mathrm{C}$. Using Transstart Tip Green qPCR supermix Kit, we conducted real-time fluorescence quantitative PCR reaction under conditions of $94{ }^{\circ} \mathrm{C}$ pre-degeneration $30 \mathrm{~s}, 94^{\circ} \mathrm{C} 5 \mathrm{~s}, 60^{\circ} \mathrm{C} 15 \mathrm{~s}, 72^{\circ} \mathrm{C} 10 \mathrm{~s}$, a total of 45 cycles. Each sample was set with three compound holes and repeated three times. 2-CT was put to indicate the relative expression of mRNA in the sample. The primer sequence were shown in the table 2

\subsection{ELISA for detection of hepatitis B virus antigen secretion}

We took the HepG2.215 cells of the logarithmic growth period, vaccinated them into the 12 orifice plate. After transfection, the cells are cultured hungrily for $6-8 \mathrm{~h}$. Then we discarded the supernatant to add fresh medium, cultured it for $18 \mathrm{~h}$, and then collected cell supernatant. We diluted with PBS in proportion to $1: 2$, and read with an enzyme marker respectively, following the instructions after incubation, using $\mathrm{HBsAg}, \mathrm{HBeAg}$ enzyme-linked immune (ELISA) Kit ( Shanghai Ke Hua Bioengineering Co., Ltd.). Then we read the OD value of each hole and calculated the relative amount of hepatitis $\mathrm{B}$ antigen based on wavelength $450 \mathrm{~nm}, 650 \mathrm{~nm}$. The formula was: relative quantity = Experimental Group $\left(\mathrm{OD}_{490}-\mathrm{OD}_{630}\right)$-control group $\left(\mathrm{OD}_{490}-\mathrm{OD}_{630}\right)$

\subsection{Statistical methods}

Statistical software graphpadprism6 was used to analyze the data. All results were expressed as mean \pm standard deviation. Independent sample t-test was used to analyze Real-time quantitative PCR result and ELISA result. The significant level difference was set as $\mathrm{P}<0.05$

\section{RESULTS}

\subsection{A1 is the most powerful peptide in the CID} section that inhibits HBV replication.

According to the CID's structure, it was divided into three sections of polypeptide: A1,A1A2,A2A3. After they were built into plasmid, we transfected it into HepG2.215 cells. qRT-PCR had detected that plasmid was expressed(Fig1A、B). QRT-PCR had detected that HBV DNA was expressed. The results showed that A1 inhibited HBV replication significantly higher than other groups, and the difference was statistically significant $(\mathrm{P}<0.05) \quad(\mathrm{Fig} 2 \mathrm{C})$. The results of Elisa showed that the expression of $\mathrm{HBsAg}$ and $\mathrm{HBeAg}$ in A1 group was significantly lower than that of other groups, and the difference was statistically significant $(\mathrm{P}<0.05)($ Fig2A、B).

\section{2 $\mathrm{A1}^{\mathrm{N}}, \mathrm{A} 1^{\mathrm{C}}$ did not have obvious antiviral function} According to the structure of A1, we divided it into two parts $\mathrm{A} 1^{\mathrm{N}}, \mathrm{A} 1^{\mathrm{C}}$ and built them into plasmids respectively (Fig.3A). The plasmid is transfected into the cell. qRT-PCR detection of plasmid activity found that plasmid expression was expression good (Fig.3B). QRT-PCR detection of HBV DNA expression showed that there was no significant change in HBV DNA expression $\mathrm{A} 1^{\mathrm{N}}, \mathrm{A} 1^{\mathrm{C}}$ compared with the blank group, and the difference was not statistically significant $(\mathrm{P}>0.05)$ (Fig.4C). Elisa was used to detect the secretion of hepatitis B surface antigen and $E$ antigen. The results of Elisa were consistent with those of qRT-PCR, and the difference was not statistically significant $(\mathrm{P}>0.05)$ (Fig.4A、B)

\section{Discussion}

IFN-A inhibits HBV replication mainly by inducing cells to produce antiviral proteins (adhesive antiviral protein $\mathrm{MxA}$, double-stranded RNA activating protein kinase PKR, 2 '-5 ' adenosine synthase 2 ' 5 ' OAS, etc.) and immunomodulatory. JAK-STAT pathway is the classic IFN signal transduction pathway. The results show that HBV interference with JAK1-STAT1 signaling pathway and antagonistic effect against viral protein is an important mechanism to cause IFN- $\alpha$ 's 
non-response. Lütgehetmann and other studies have found that $\mathrm{HBV}$ polymerase inhibits the transcription activity of the original promoter ISRE of interferon stimulation gene response and the expression of interferon stimulating genes such as STAT1 and ISG15, inhibiting the nuclear transposition of STAT1[8]. HBV core antigen $\mathrm{HBcAg}$ can be combined with the promoter region of the $\mathrm{MxA}$ gene to reduce the expression of MxA protein[9]. HBV thereby evades IFN- $\alpha$-induced immune removal, resulting in IFN- $\alpha$ treatment failure or not long-term response. In the antiviral protein induced by interferon, MxA protein is the most closely related to its antiviral function. The study has already found that removing the gene of $\mathrm{MxA}$, the inhibitory effect of interferon on the influenza A-endemic cold virus infected with A549 cells in vitro disappears[10]; Clinical data shows that the expression level of MxA protein in host cells is positively correlated with the response of type I interferon and is considered a biomarker for clinical antiviral therapy of type I interferon[11, 12]. Interestingly, individual expression of $\mathrm{MxA}$ alone can significantly inhibit HBV cell models and virus replication in $\mathrm{HBV}$ transgenic mice, suggesting that its anti-HBV function does not rely on IFN-A signals[5, 13]. In addition, our study finds that $\mathrm{MxA}$ is able to interact with HBV to play a direct antiviral effect [6]. An article in "Science" reports a class of non-nucleoside HBV inhibitors-heterocyclic Two hydrogen compounds Bay 41-4109, which can interfere with the assembly of viral casings, promote the solution of nuclear casings and play a powerful anti-HBV role. Preclinical data shows that the anti-HBV activity of Bay41-4109 is nearly 60 times stronger than that of nucleoside listed drug lamivudine[7], and further targeted compound GLS4 has a stronger inhibition of HBV DNA replication activity, regardless of whether lamivudine resistant strains or adfovir resistant strains are equally sensitive to such drugs [14]. The Assembly of nuclear casings is increasingly becoming a dominant target for intervention in HBV replication and the development of new drugs[15, 16].

According to our previous research results, the Central mutual CID of MxA protein was the anti-HBV crucial region. In this study, CID was divided into three parts by means of genetic engineering combined with the characteristics of its structure: A1, A1A2 and A2A3. The three domain structures were constructed into plasmids, respectively. Then these plasmids transfected into HepG2.215 cells containing HBV and the effect of three different peptide segments on the virus were detected. The results showed that some of the antiviral ability of A1 was the strongest, and then according to the structural characteristics of $\mathrm{A} 1$, it was divided into two parts, $\mathrm{N}$ end: $\mathrm{A} 1^{\mathrm{N}} ; \mathrm{C}$-Terminal $\mathrm{A} 1^{\mathrm{C}}$, respectively, to build plasmid which were used to transfect HepG2.215 cell. Comparing its antiviral ability, the results show that the anti-virus ability of $\mathrm{A} 1^{\mathrm{N}}$ and $\mathrm{A} 1^{\mathrm{C}}$ are not as strong as A1. In this study, the method of plasmid construction was used to shorten the $76 \mathrm{KD}$ size MxA protein to $7 \mathrm{KD}$ size polypeptide, which greatly improves the bioavailability, and reduces the difficulty of developing the drug precursor. These results has provided a new idea for the development of new drugs against hepatitis B. The antiviral ability of the A1 peptide segment can be further validated by protein purification and determined by its $\mathrm{IC}_{50}$, and the MxA protein also has the ability to resist RNA viruses, which can also be applied to this peptide segment.

\section{DISCLOSURE ATATEMENT}

The authors declare that they have no conflict of interest.

\begin{tabular}{cll}
\hline Gene & \multicolumn{1}{c}{ Forward } & \multicolumn{1}{c}{ Reverse } \\
\hline A1 $^{\mathrm{N}}$ & GCCCGGGCGGATCCCGAAGACGAAAA & TGATATCGAATTCCTTTATTGCATGAGAGCA \\
A1 & GCCCGGGCGGATCCCCTGTTTACCAG & TGATATCGAATTCCTTTACTGGATTTTTCTA \\
A1 & GCCCGGGCGGATCCCGAAGACGAAAA & TGATATCGAATTCCTTTACTGGATTTTTCTA \\
A1A2 & GCCCGGGCGGATCCCGAAGACGAAAA & TGATATCGAATTCCTTTAAAAATTTTTTATC \\
A2A3 & GCCCGGGCGGATCCCGTGAATTACAG & TGATATCGAATTCCTTTA \\
CID & CGGGATCCC ATGGGAGAGGCAAGG & CGGAATTCTCAGGCTGATTGCCC \\
\hline
\end{tabular}

Table1 Primer for peptide plasmid

Table2 Primers for real time quantitative RT-PC

\begin{tabular}{ccc}
\hline Gene & Forward & Reverse \\
\hline GAPDH & GGAGCCAAAAGGGTCATCATCT & AGGGGCCATCCACAGTCTTCT \\
HBV DNA & & GGAGGGATACATAGAGGTTCCTT \\
Myc & GATCCTCTTCAGAGATGAGTTTC \\
\hline
\end{tabular}


Fig. 1
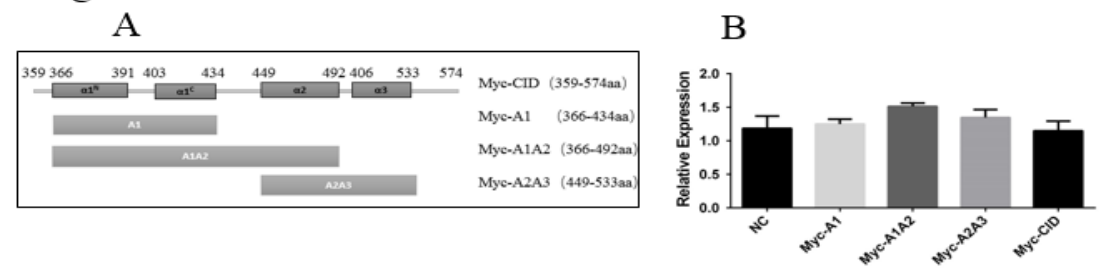

Fig 1 The structure of plasmid and the expression of myc in HepG2.215 cells. CID, A1,A1A2, A2A3 structure concept map (A). Detection of MYC expression in CID, A1,A1A2 and A2A3 groups by real-time fluorescence quantitative PCR (B).

\section{Fig.2}

A

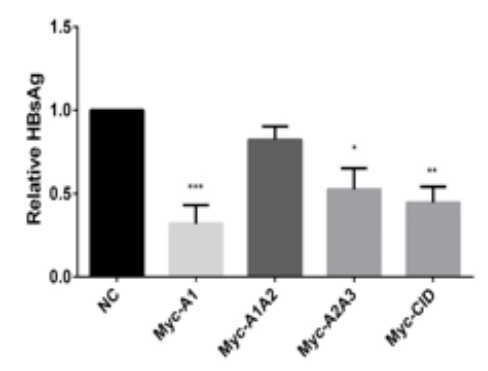

B

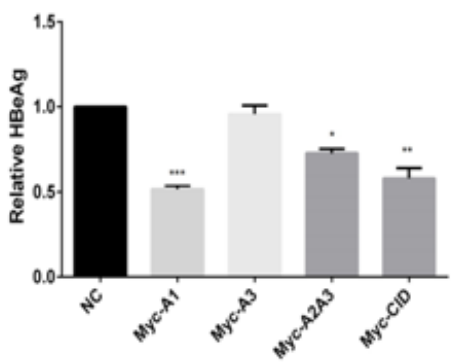

$\mathrm{C}$

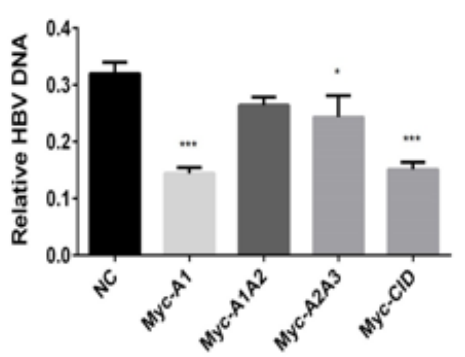

Fig 2 The secretion of cell antigen and the expression of HBV DNA in each group after transfection of Plasmid. The HBsAg expression of CID, A1, A1A2 andA2A3 groups was compared by ELISA kit detection (A). The HBeAg expression of CID, A1, A1A2 and A2A3 groups was compared by ELISA kit detection (B). The expression of CID, A1, A1A2 and A2A3 groups was compared by qRT-PCR. The results are expressed by relative expression of HBV DNA/relative expression of MYC. All results are expressed by an average \pm standard deviation, with Multiple Comparison using the $\mathrm{T}$ test. The difference in the level of salience is set to $\mathrm{p}<0.05, \mathrm{n} \geq 3,{ }^{*} \mathrm{P}<0.05, * *$ $\mathrm{P}<0.01, * * * \mathrm{P}<0.001$

\section{Fig.3}

A

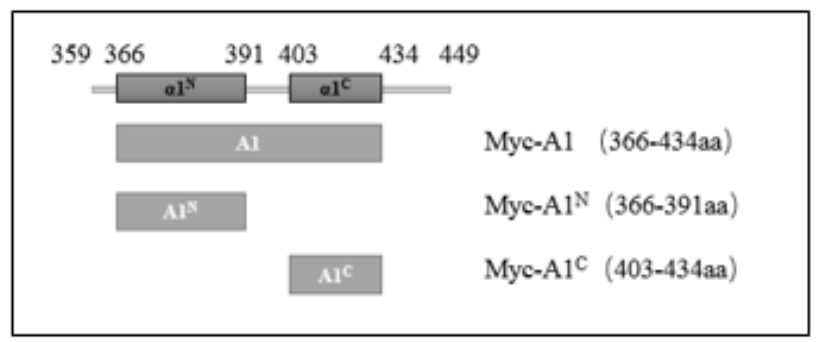

B

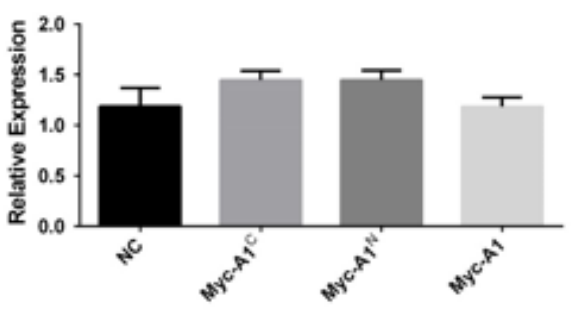

Fig 3 The structure of plasmid and the expression of myc in $\mathbf{H e p G 2 . 2 1 5}$ cells. $\mathrm{A} 1, \mathrm{~A} 1^{\mathrm{C}}$ and $\mathrm{A} 1^{\mathrm{N}}$ structure concept map (A) Detection of $\mathrm{A} 1, \mathrm{~A} 1^{\mathrm{C}}$ and $\mathrm{A} 1^{\mathrm{N}}$ group $\mathrm{MYC}$ expression detection by real-time fluorescence quantitative PCR (B) 
Fig.4

A

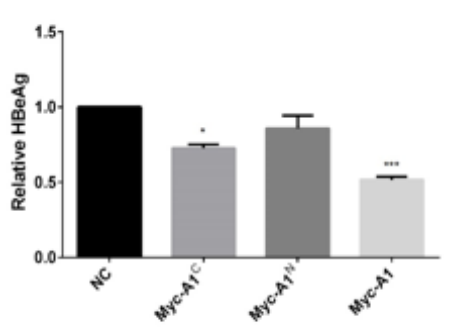

B

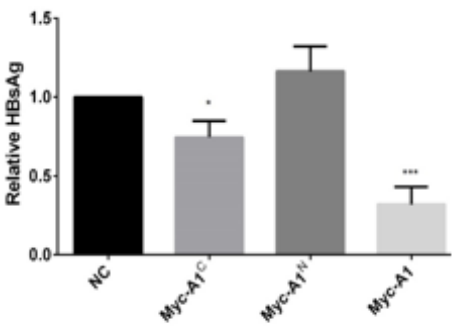

$\mathrm{C}$

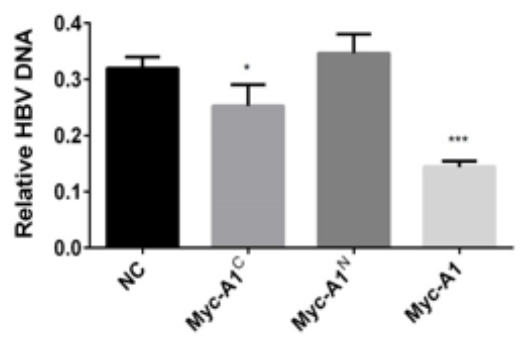

Fig 4The secretion of cell antigen and the expression of HBV DNA in each group after transfection of Plasmid. The HBeAg expression of $\mathrm{A} 1, \mathrm{~A} 1^{\mathrm{C}}$ and $\mathrm{A} 1^{\mathrm{N}}$ groups was compared by Elisa Kit (A) The $\alpha 1, \alpha 1 n$ expression of $\alpha 1 \mathrm{c}$ and HBsAg groups was measured by ELISA Kit (B). Detection and comparison of HBV in A1, A1 ${ }^{\mathrm{C}}$ and $\mathrm{A} 1^{\mathrm{N}}$ groups by qRT-PCR DNA expression. The results are expressed by relative expression of HBV DNA/relative expression of MYC. (C). All results are expressed by an average \pm standard deviation, with Multiple Comparison using the $\mathrm{T}$ test. The difference in the level of salience is set to $\mathrm{p}<0.05, \mathrm{n} \geq 3,{ }^{*} \mathrm{P}<0.05, * * \mathrm{P}<0.01, * * * \mathrm{P}<0.001$.

\section{References:}

1. K. N. D. kim k H, seong B L, "Discovery and development of anti-HBV agents and their resistance," Molecules, vol. 15, p. 30 , 2010 .

2. N. M. Lozano R, Foreman K, Lim S, Shibuya K, Aboyans V, Abraham J, Adair T, Aggarwal R, Ahn SY, "Global and regional mortality from 235 causes of death for 20 age groups in 1990 and 2010_ a systematic analysis for the Global Burden of Disease Study 2010," Lancet, vol. 380, p. 33, 2012.

3. M. B. Lok AS, "AASLD Practice Guidelines.Chronic hepatitis B update of therapeutic guidelines," Gastroentero, vol. 12, p. 5, 2004.

4. Senko Tsukuda, 2 Koichi Watashi,1,3,4 Taichi Hojima,5 Masanori Isogawa,6 Masashi Iwamoto,1,3 Katsumi Omagari,6, H. A. Ryosuke Suzuki, 1 Soichi Kojima,2 Masaya Sugiyama,7 Akiko Saito,5 Yasuhito Tanaka,6 Masashi Mizokami,7, and a. T. W. Camille Sureau, "A New Class of Hepatitis B and D Virus Entry Inhibitors, Proanthocyanidin and Its Analogs, That Directly Act on the Viral Large Surface Proteins," HEPATOLOGY, vol. 65, p. 13, 2017.

5. C. Peltekian, E. Gordien, F. Garreau, V. Meas-Yedid, P. Soussan, V. Willams, et al., "Human MxA protein participates to the interferon-related inhibition of hepatitis B virus replication in female transgenic mice," J Hepatol, vol. 43, pp. 965-72, Dec 2005.

6. N. Li, L. Zhang, L. Chen, W. Feng, Y. Xu, F. Chen, et al., "MxA inhibits hepatitis B virus replication by interaction with hepatitis B core antigen," Hepatology, vol. 56, pp. 803-11, Sep 2012.

7. S. C. Deres K, Paessens A, Goldmann S, Hacker HJ, Weber O, Krämer T, Niewöhner, P. U. U, Stoltefuss J, Graef E, Koletzki D, Masantschek RN,Reimann A, Jaeger R, and B. B. Gross R, Schlemmer KH, Haebich D, R ü bsamen-Waigmann H., "Inhibition of hepatitis B virus replication by drug-induced depletion of nucleocapsids," Science, vol. 299, p. 4, 2003.

8. M. Lutgehetmann, T. Bornscheuer, T. Volz, L. Allweiss, J. H. Bockmann, J. M. Pollok, et al., "Hepatitis B virus limits response of human hepatocytes to interferon-alpha in chimeric mice," Gastroenterology, vol. 140, p. 12, Jun 2011.

9. M. Fernandez, J. A. Quiroga, and V. Carreno, "Hepatitis B virus downregulates the human interferon-inducible MxA promoter through direct interaction of precore/core proteins," J Gen Virol, vol. 84 , pp. 2073-82, Aug 2003.

10. H. Xiao, M. J. Killip, P. Staeheli, R. E. Randall, and D. Jackson, "The human interferon-induced MxA protein inhibits early stages of influenza A virus infection by retaining the incoming viral genome in the cytoplasm," J Virol, vol. 87, pp. 13053-8, Dec 2013.

11. M. Wadhwa, M. Subramanyam, S. Goelz, J. Goyal, V. Jethwa, W. Jones, et al., "Use of a standardized MxA protein measurement-based assay for validation of assays for the assessment of neutralizing antibodies against interferon-beta," $J$ Interferon Cytokine Res, vol. 33, pp. 660-71, Nov 2013.

12. N. I. Maria, Z. Brkic, M. Waris, C. G. van Helden-Meeuwsen, K. Heezen, J. P. van de Merwe, et al., "MxA as a clinically applicable biomarker for identifying systemic interferon type I in primary Sjogren's syndrome," Ann Rheum Dis, vol. 73, pp. 1052-9, Jun 2014.

13. E. Gordien, O. Rosmorduc, C. Peltekian, F. Garreau, C. Brechot, and D. Kremsdorf, "Inhibition of hepatitis B virus replication by the interferon-inducible MxA protein," $J$ Virol, vol. 75, pp. 2684-91, Mar 2001.

14. G. Wu, B. Liu, Y. Zhang, J. Li, A. Arzumanyan, M. M. Clayton, et al., "Preclinical characterization of GLS4, an inhibitor of hepatitis B virus core particle assembly," Antimicrob Agents Chemother, vol. 57, pp. 5344-54, Nov 2013.

15. M. R. Campagna, F. Liu, R. Mao, C. Mills, D. Cai, F. Guo, et al., "Sulfamoylbenzamide derivatives inhibit the assembly of hepatitis B virus nucleocapsids," J Virol, vol. 87, pp. 6931-42, Jun 2013.

16. M. H. Cho, J. S. Song, H. J. Kim, S. G. Park, and G. Jung, "Structure-based design and biochemical evaluation of sulfanilamide derivatives as hepatitis B virus capsid assembly inhibitors," J Enzyme Inhib Med Chem, vol. 28, pp. 916-25, Oct 2013. 